\title{
Enhanced Osseointegration of a Modified Titanium Implant with Bound Phospho-Threonine: A Preliminary In Vivo Study
}

\author{
Yohei Okazaki, Kazuya Doi *, Yoshifumi Oki, Reiko Kobatake, Yasuhiko Abe and \\ Kazuhiro Tsuga
}

Department of Advanced Prosthodontics, Hiroshima University Graduate School of Biomedical and Health Sciences, 1-2-3, Kasumi, Minami-ku, Hiroshima 734-8553, Japan; okazaki-yoh@hiroshima-u.ac.jp (Y.Oka.); yos-oki14@hiroshima-u.ac.jp (Y.Oki); Reiko1122@hiroshima-u.ac.jp (R.K.); abey@hiroshima-u.ac.jp (Y.A.); tsuga@hiroshima-u.ac.jp (K.T.)

* Correspondence: kazuya17@hiroshima-u.ac.jp; Tel.: +81-82-257-5677; Fax: +81-82-257-5679

Academic Editor: Francesco Puoci

Received: 27 February 2017; Accepted: 18 May 2017; Published: 25 May 2017

\begin{abstract}
Implant surface topography is a key factor in achieving osseointegration. 1-Threonine can be chemically and stably bonded to titanium surfaces by phosphorylation. This study investigated the degree of in vivo osseointegration of an implant with a novel o-phospho-l-threonine ( $\mathrm{p}$-Thr)-binding surface. MC3T3-E1 cells were seeded on the $p$-Thr binding surface and machined surface disks, and initial cell attachment was evaluated. p-Thr-binding and machined surface implants were tested in vivo by implantation into the femurs of three male New Zealand white rabbits, and the osseointegration was assessed by measurement of removal torque (RT) and bone-implant contact (BIC) ratio. Initial cell attachment was greater for the $\mathrm{p}$-Thr-binding than for the machined surface implant group $(P<0.05)$. In addition, RT and BIC values were higher for the $\mathrm{p}$-Thr-binding surface than for the machined surface $(P<0.05)$. These results indicate that our implant with a p-Thr-binding surface can achieve enhanced osseointegration.
\end{abstract}

Keywords: surface topography; titanium surface modification; o-phospho-l-threonine

\section{Introduction}

The clinical success of oral implants is related to their early osseointegration, which in turn depends on different factors, including implant surface topography and design [1]. Surface topography plays a role in the osteointegration of implants [2]. The most common topographical modification is surface roughness, which is achieved by acid etching, sandblasting, or oxidization. The microtopography provides accelerated differentiation of osteogenic cell [3]. The roughness of dental implant surfaces (also known as the $S_{a}$ value) can be classified as smooth $(0.0-0.4 \mu \mathrm{m})$, minimally rough $(0.5-1.0 \mu \mathrm{m})$, moderately rough $(1.0-2.0 \mu \mathrm{m})$, or rough $(>2.0 \mu \mathrm{m})$ [4]. Many studies have reported that a rough surface promotes bone anchoring and biomechanical stability of implants [5] and enhances cell initial attachment and differentiation into osteoblasts [6,7]. These modification methods affect osteogenic cells activity because they modify the adsorption of proteins from biological fluids. Positively charged serum proteins attach to negatively charged titanium surfaces because of a difference in electrostatic potential [8]. Osteoblasts are then adsorbed onto the titanium, with integrin expressed by osteoblasts acting as receptors for the serum protein, thereby initiating bone formation. Thus, the binding of protein to the implant surface can enhance osseointegration. Rough surfaces are also superior to smooth surfaces in terms of osseointegration. In our previous study, we showed that stability was lower for implants with a machined surface than for those with a TiUnite ${ }^{\mathrm{TM}}$ (Gothenburg, 
Sweden) surface $\left(S_{a}: 0.9\right.$ vs. $\left.1.1 \mu \mathrm{m}\right)$ [9]. However, greater surface roughness increases biofilm formation on the implant surface and abutment, thereby increasing the risk of peri-implantitis $[10,11]$. There is therefore a need for methods that enhance bone formation while increasing resistance to peri-implantitis. In our previous study, a phosphorylated amino acid (o-phospho-l-threonine (p-Thr)) was bonded to a titanium surface treated with $\mathrm{HCl}$ [12]. To take advantage of this material, in the present study, we designed a novel type of implant surface that promotes cell attachment and has a smoother surface topography. We speculated that $\mathrm{p}$-Thr on the implant surface would enhance cell attachment and osteoblast activity in vivo, and tested this hypothesis by evaluating the osseointegration of the implants in rabbits. Therefore, the purpose of the present study was to investigate the effect of a novel p-Thr binding surface on osseointegration in vivo.

\section{Results and Discussion}

\subsection{Results}

\subsubsection{Evaluation of Surface Roughness}

p-Thr-binding and machined (control) surfaces were examined by scanning electron microscopy (SEM) (Figure 1).
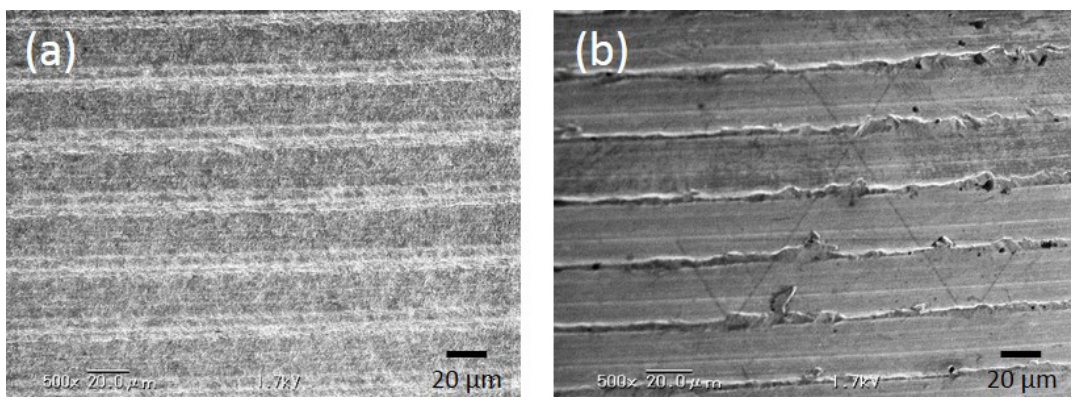

Figure 1. Scanning electron microscopy (SEM) analysis. (a) p-Thr-binding surface; (b) Machined surface. Both groups showed traces of machine tuning. The $\mathrm{p}$-Thr-binding surface had a finer surface structure than the control.

Both groups showed evidence of machine turning, but the $\mathrm{p}$-Thr binding surface was rougher than the control surface $\left(R_{a}: 0.41 \pm 0.01\right.$ vs. $\left.0.24 \pm 0.02 ; P<0.001\right)$ (Table 1 ).

Table 1. Surface roughness.

\begin{tabular}{cc}
\hline Group & $\boldsymbol{R}_{\boldsymbol{a}} \boldsymbol{\mu \mathrm { m } ( \mathrm { SD } )}$ \\
\hline p-Thr & $0.41(0.01)^{*}$ \\
Control & $0.24(0.02)$ \\
\hline SD: standard deviation; ${ }^{*} P<0.001$.
\end{tabular}

\subsubsection{Measurement of Initial Cell Attachment}

The degree of initial cell attachment to the p-Thr-binding surface and machined surface was evaluated after $24 \mathrm{~h}$ of incubation (Figure 2). Cell attachment was greater in the $\mathrm{p}$-Thr binding surface than in the control $(0.22 \pm 0.00$ vs. $0.18 \pm 0.00 ; P<0.001)$. 


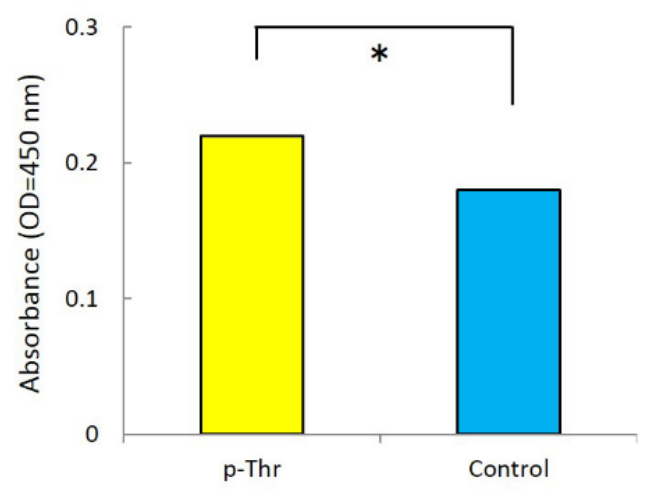

Figure 2. Initial cell attachment values. The p-Thr-binding group showed higher cell attachment than the control $(P<0.001)$.

\subsubsection{Measurement of Removal Torque and Bone-Implant Contact}

Removal torque (RT) was measured using a digital torque gauge (Figure 3). The RT value was higher in the p-Thr-binding condition than in the control $(10.77 \pm 2.34$ vs. $7.67 \pm 1.59 \mathrm{~N} \cdot \mathrm{cm} ; P=0.011)$.

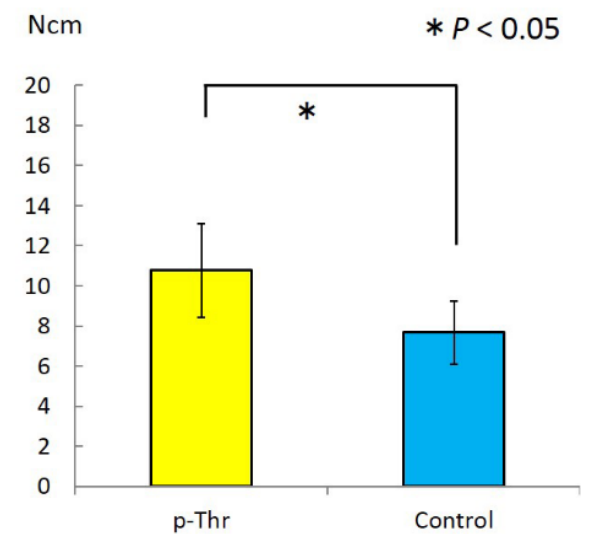

Figure 3. Removal torque (RT) values. The p-Thr-binding group showed a higher RT value than the control $(P=0.011)$.

A similar trend was observed for the bone-implant contact (BIC) ratio $(62.2 \% \pm 6.1 \%$ vs. $38.1 \% \pm 11.3 ; P=0.016$ ) (Figure 4).

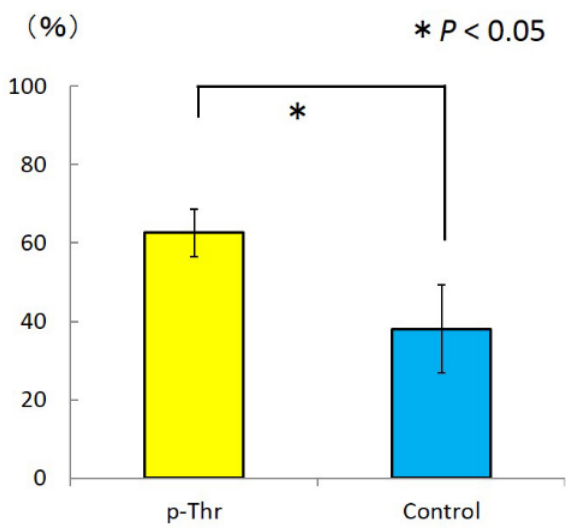

Figure 4. Bone-implant contact (BIC) ratio. The $\mathrm{p}$-Thr-binding group showed a higher BIC ratio value than the control $(P=0.016)$. 


\subsubsection{Histological Observations}

Osseointegration was detected for both types of implant (Figures 5 and 6). The p-Thr binding surface made contact with bone to a greater degree than the control implant, particularly at the collar portion of the implant surface; bone formation occurred towards the cortical bone portion near the bottom of the implant, where the bone marrow was located.
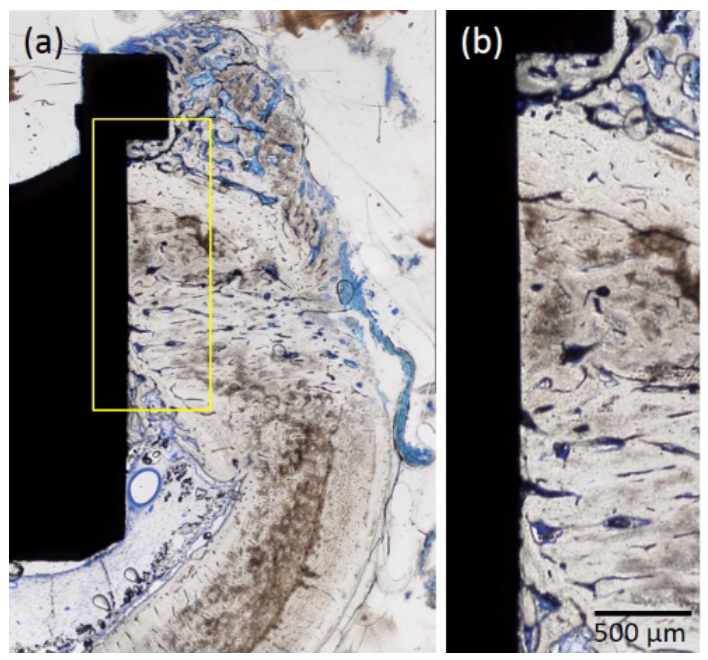

Figure 5. Histological analysis of specimens of the p-Thr-binding implant. (a) Osseointegration was observed at the bone/implant surface interface. Bone formation occurred towards the cortical bone portion near the bottom of the implant, where the bone marrow was located; (b) The implant surface made contact with bone at the collar portion. Original magnification: $40 \times$; Toluidine Blue staining.

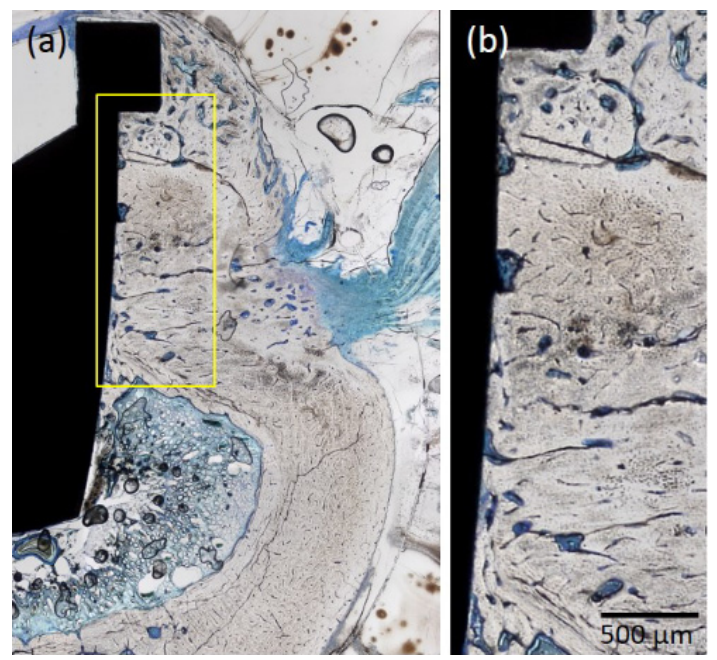

Figure 6. Histological analysis of specimens from the machined implant (control). (a) Osseointegration was observed at the bone/implant surface interface; (b) The implant surface made contact with bone, but to a lesser degree than that observed for the $\mathrm{p}$-Thr-binding surface. Original magnification: $40 \times$; Toluidine Blue staining.

\subsection{Discussion}

The results of this study indicate that a p-Thr-binding surface can increase osseointegration as determined by RT and BIC values. Rough implant surfaces can achieve greater primary stability because of increased contact between the surface and surrounding bone, which enhances osseointegration by stimulating bone growth, thereby reducing the risk of implant failure during the 
early healing phase [13]. Recent studies have suggested that rough surfaces are associated with a higher risk of peri-implantitis than smooth surfaces over a long period, as they also permit attachment of bacterial cells $[14,15]$. However, smooth and rough surfaces are similar in terms of osseointegration capacity at secondary stability during the healing phase [13]. The extent of bone resorption resulting from experimental peri-implantitis was greater for implants with a TiUnite surface $\left(R_{a} 1.1\right)$ than for those with a machine-tuned surface [14].

Phosphate has been found to have a high affinity for titanium oxide surfaces [16]. Phosphoric acid molecules covalently attached to a titanium surface may form a scaffold for new bone formation, leading to bonding between implant and host tissue [17]. Amino acids such as 1-serine, 1-tyrosine, and l-threonine are low-molecular weight molecules that can be bonded to a titanium surface by phosphorylation. In particular, the peptide bond in 1-threonine is rarely hydrolyzed under physiological conditions. Our previous study demonstrated that $\mathrm{p}$-Thr could be chemically bonded to a titanium surface treated with $\mathrm{HCl}$. However, the surface topography was slightly rough because of the $\mathrm{HCl}$ treatment. In the present study, Ra of the p-Thr binding implant was 0.41 ; however, the degree of roughness was classified as smooth [4]. In contrast to the untreated control surface, the p-Thr-binding surface promoted cell attachment in the healing phase, which induced bone formation on the surface. Osseointegration was detected in both groups; however, BIC was greater in the $\mathrm{p}$-Thr binding group. This indicates that the osteoinduction capacity of the $\mathrm{p}$-Thr binding surface was superior to that of the machined surface.

Implant stability reflects osseointegration and is considered an accurate measure of the success of an implant [18]. Osseointegration can be evaluated by resonance frequency analysis (RFA), a noninvasive method that continuously measures implant stability to determine whether a sufficient amount of bone surrounds the implant and whether the two materials have achieved integration $[19,20]$. However, this method has limited applications, for instance in commercial dental implants. Furthermore, RFA is conducted on a limited number of cross-sections and may not reflect the integration of the whole implant. To evaluate osseointegration in our animal model, we relied on histological observation and histomorphometric measurements. Specifically, we measured BIC and RT and found that the values for both parameters were higher for the implant with the p-Thr-binding surface than for the control, indicating that more bone was formed on the former surface. BIC and RFA values are related, and a positive correlation exists between increases in the implant stability quotient and BIC [21,22]. RT also provides a quantitative assessment of osseointegration of the entire implant, and is influenced by cortical bone thickness [23]. Moreover, surface topography (including roughness) influences cell attachment and differentiation and can modulate the speed of bone formation around the implant during the healing phase, explaining the higher BIC and RT values for the p-Thr-binding surface than for machined implants.

Based on the results presented here, we suggest that osseointegration can be effectively achieved with the p-Thr-binding surface implant in vivo. Future studies will evaluate the resistance of implants with rough surfaces to peri-implantitis to clarify the advantages of this novel type of surface.

\section{Materials and Methods}

\subsection{Fabrication of $p$-Thr-Binding Surface}

The $\mathrm{p}$-Thr binding surface was fabricated as described in a previous study [12]. Machined surface titanium disks (diameter: $13.0 \mathrm{~mm}$, height: $1.0 \mathrm{~mm}$ ) and the implant body (diameter: $3.0 \mathrm{~mm}$, length: $5.0 \mathrm{~mm}$ ) were custom-fabricated (Figure 7) from pure titanium (JIS 2 grade; Nishimura Co., Fukui, Japan), and then subjected to ultrasonic cleaning with $10 \mathrm{~N} \mathrm{HCl}$ for $30 \mathrm{~min}$, followed by rinsing with ultrapure water. The disks and implant were immersed in $50 \mathrm{mM} \mathrm{p}-\mathrm{Thr}$ (molecular weight: 181.08; Sigma-Aldrich, Tokyo, Japan) at $37^{\circ} \mathrm{C}$ for $12 \mathrm{~h}$, then cleaned again with ultrapure water. The untreated disks and implants were used as a control. 

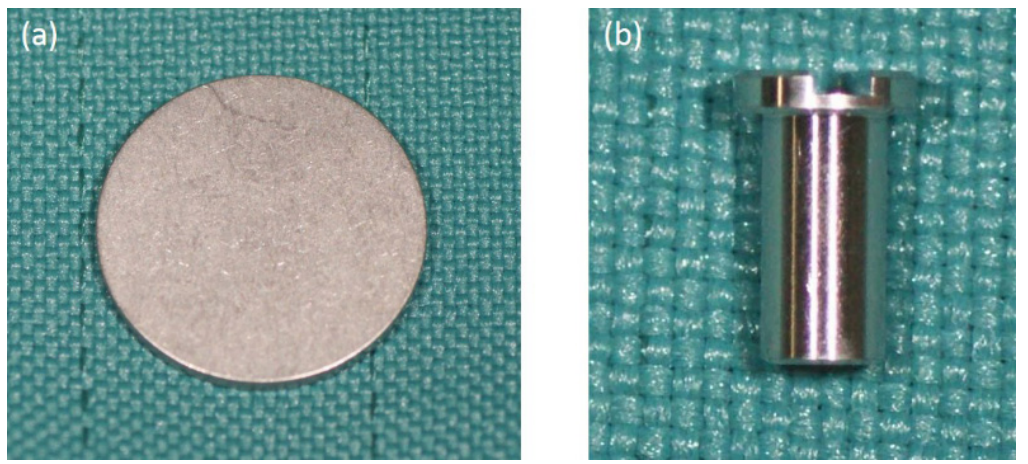

Figure 7. Samples of pure machined titanium. (a) Disk type: diameter $=13.0 \mathrm{~mm}$; height $=1.0 \mathrm{~mm}$; (b) Implant type: diameter $=3.0 \mathrm{~mm}$, length $=5.0 \mathrm{~mm}$.

\subsection{Scanning Electron Microscopy and Surface Roughness Measurement}

The $R_{a}$ of each sample was evaluated by confocal laser scanning microscopy (VK-8500; Keyence, Osaka, Japan). The $R_{a}$ value $(\mu \mathrm{m})$ was defined as the average value of five different areas $\left(100 \times 100 \mu \mathrm{m}^{2}\right)$.

\subsection{Initial Cell Attachment}

MC3T3-E1 osteoblast-like cells were seeded on the p-Thr binding surface and machined surface titanium disk at a density of $1.0 \times 10^{5}$ cells/well and cultured in Dulbecco's Modified Eagle Medium containing $10 \%$ fetal bovine serum and $1 \%$ penicillin-streptomycin for approximately $24 \mathrm{~h}$ at $37^{\circ} \mathrm{C}$ under a $5 \% \mathrm{CO}_{2}$ atmosphere to allow initial attachment. Cell Counting Kit-8 (Dojindo Laboratories, Kumamoto, Japan) was used to measure the absorbance of the $\mathrm{p}$-Thr binding surface at a wavelength of $450 \mathrm{~nm}$.

\subsection{In Vivo Assessment of Osseointegration}

The experimental protocol conformed to the regulations established in the current version of the Japan Law on the Protection of Animals. The study was approved by the Research Facilities Committee for Laboratory Animal Science at Hiroshima University School of Medicine, Hiroshima, Japan (A-11-5-3). Three male New Zealand White rabbits (17 weeks old, 3.0-3.5 kg) were used. Surgeries were performed under general anesthesia with sodium pentobarbital (Somnopentyl, $10 \mathrm{mg} / \mathrm{kg}$ by intravenous injection; Kyoritsu Seiyaku Corp., Tokyo, Japan).

Muscle and periosteal flaps were made on the left and right femurs, and two implant sockets (diameter: $3 \mathrm{~mm}$, depth: $5 \mathrm{~mm}$ ) were prepared on each side. The $\mathrm{p}$-Thr binding surface and machined implants were placed in the right and left bone sockets, respectively $(n=6)$ (Figure 8$)$, and 4 weeks later, the RT of each implant was recorded using a digital torque gauge (BTG-E100CN; Tonichi, Tokyo, Japan) $(n=3)$.

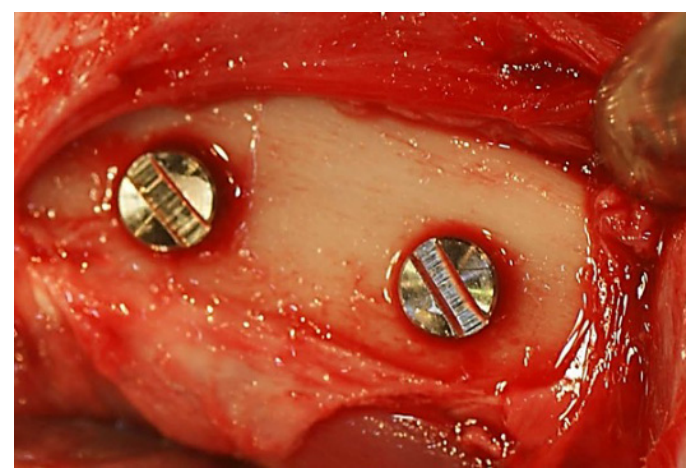

Figure 8. Implant placement. Implants were inserted into the bone socket in the bilateral femurs. 
The animals were sacrificed after measurements were obtained, and bone tissue blocks including the implant were harvested and immediately fixed in $10 \%$ buffered formalin for 10 days. Tissue blocks containing the implant were dehydrated in a graded series of ethanol, cleared with a styrene monomer, and then embedded in light-polymerized polyester resin (Technovit 7200 VLC, Kulzer, Hanau, Germany). The resin block was photopolymerized (BS5000, Exakt Aparatebau, Norderstedt, Germany), and the specimens were cross-sectioned with a high-precision diamond disk to obtain sections with a thickness of $200 \mu \mathrm{m}$. Non-decalcified specimens were ground to a thickness of approximately $70 \mu \mathrm{m}$ (MG5000, Exakt Aparatebau), and sections were stained with Toluidine Blue.

\subsection{Histological and Histomorphometric Evaluation}

Sections were visualized by light microscopy (BZ-9000; Keyence, Osaka, Japan). Images were digitized, and histomorphometric analysis was performed using ImageJ software (National Institutes of Health, Bethesda, MD, USA). The BIC ratio was determined using ImageJ as the ratio of the contact length of the newly formed bone relative to the total length from the bottom to the top of the implant $(n=3)$.

\subsection{Statistical Analysis}

Data are presented as the mean \pm standard deviation and were analyzed using Mann-Whitney $U$ test. Statistical significance was defined as $P<0.05$.

\section{Conclusions}

These results indicate that our implant with a p-Thr-binding surface can achieve enhanced osseointegration.

Acknowledgments: This study was supported by a Scientific Research Grant (No. 15K11160) from the Japan Society for the Promotion of Science.

Author Contributions: Conceived and designed experiments: Kazuya Doi, Yohei Okazaki, Yasuhiko Abe. Performed experiments: Kazuya Doi, Yohei Okazaki, Yoshifumi Oki. Analyzed the data: Kazuya Doi, Yohei Okazaki, Reiko Kobatake. Contributed reagents/materials/analysis tools: Wrote the paper: Kazuya Doi, Yohei Okazaki, Kazuhiro Tsuga.

Conflicts of Interest: The authors declare no conflict of interest.

\section{References}

1. Albrektsson, T.; Johansson, C.; Lundgren, A.K.; Sul, Y.; Gottlow, J. Experimental studies on oxidezed implants. A histomorphometrical and biomechanical analysis. Appl. Osseointegr. Res. 2000, 1, 21-24.

2. Surmenev, R.A.; Surmeneva, M.A.; Ivanova, A.A. Significance of calcium phosphate coatings for the enhancement of new bone osteogenesis-A review. Acta Biomater. 2014, 10, 557-579. [CrossRef] [PubMed]

3. Schwartz, Z.; Lohmann, C.H.; Oefinger, J.; Bonewald, L.F.; Dean, D.D.; Boyan, B.D. Implant surface characteristics modulate differentiation behavior of cells in the osteoblastic lineage. Adv. Dent. Res. 1999, 13, 38-48. [CrossRef] [PubMed]

4. Albrektsson, T.; Wennerberg, A. Oral implant surfaces: Part 1-Review focusing on topographic and chemical properties of different surfaces and in vivo responses to them. Int. J. Prosthodont. 2004, 17, 536-543. [PubMed]

5. Le Guéhennec, L.; Soueidan, A.; Layrolle, P.; Amouriq, Y. Surface treatments of titanium dental implants for rapid osseointegration. Dent. Mater. 2007, 23, 844-854. [CrossRef] [PubMed]

6. Masaki, C.; Schneider, G.B.; Zaharias, R.; Seabold, D.; Stanford, C. Effects of implant surface microtopography on osteoblast gene expression. Clin. Oral Implant. Res. 2005, 16, 650-656. [CrossRef] [PubMed]

7. Zhao, G.; Zinger, O.; Schwartz, Z.; Wieland, M.; Landolt, D.; Boyan, B.D. Osteoblast-like cells are sensitive to submicron-scale surface structure. Clin. Oral Implant. Res. 2006, 17, 258-264. [CrossRef] [PubMed]

8. Boehm, H.P. Acidic and basic properties of hydroxylated metal oxide surfaces. Discuss. Faraday Soc. 1971, 52, 264-275. [CrossRef] 
9. Oue, H.; Doi, K.; Oki, Y.; Makihara, Y.; Kubo, T.; Perrotti, V.; Piattelli, A.; Akagawa, Y.; Tsuga, K. Influence of implant surface topography on primary stability in a standardized osteoporosis rabbit model study. J. Funct. Biomater. 2015, 6, 143-152. [CrossRef] [PubMed]

10. Esposito, M.; Hirsch, J.M.; Lekholm, U.; Thomsen, P. Biological factors contributing to failures of osseointegrated oral implants, (II). Etiopathogenesis. Eur. J. Oral Sci. 1998, 106, 721-764. [CrossRef] [PubMed]

11. Subramani, K.; Jung, R.E.; Molenberg, A.; Hammerle, C.H. Biofilm on dental implants: A review of the literature. Int. J. Oral Maxillofac. Implant. 2009, 24, 616-626.

12. Abe, Y.; Hiasa, K.; Takeuchi, M.; Yoshida, Y.; Suzuki, K.; Akagawa, Y. New surface modification of titanium implant with phospho-amino acid. Dent. Mater. J. 2005, 24, 536-540. [CrossRef] [PubMed]

13. Glauser, R.; Portmann, M.; Ruhstaller, P.; Lundgren, A.K.; Hämmerle, C.; Gottlow, J. Stability measurements of immediately loaded machined and oxidized implants in the posterior maxilla. A comparative clinical study using resonance frequency analysis. Appl. Osseontegration Res. 2001, 2, 27-29.

14. Albouy, J.P.; Abrahamsson, I.; Berglundh, T. Spontaneous progression of experimental peri-implantitis at implants with different surface characteristics: an experimental study in dogs. J. Clin. Periodontol. 2012, 39, 182-187. [CrossRef] [PubMed]

15. Al-Ahmad, A.; Wiedmann-Al-Ahmad, M.; Fackler, A.; Follo, M.; Hellwig, E.; Bächle, M.; Hannig, C.; Han, J.S.; Wolkewitz, M.; Kohal, R. In vivo study of the initial bacterial adhesion on different implant materials. Arch. Oral Biol. 2013, 58, 1139-1147. [CrossRef] [PubMed]

16. Healy, K.E.; Ducheyne, P. The mechanisms of passive dissolution of titanium in a model physiological environment. J. Biomed. Mater. Res. 1992, 26, 319-338. [CrossRef] [PubMed]

17. Viornery, C.; Guenther, H.L.; Aronsson, B.O.; Péchy, P.; Descouts, P.; Grätzel, M. Osteoblast culture on polished titanium disks modified with phosphonic acids. J. Biomed. Mater. Res. 2002, 62, 149-155. [CrossRef] [PubMed]

18. Zarb, G.A.; Schmitt, A. Osseointegration and the edentulous predicament. The 10-year-old Toronto study. Br. Dent. J. 1991, 70, 439-444. [CrossRef]

19. Meredith, N.; Alleyne, D.; Cawley, P. Quantitative determination of the stability of the implant-tissue interface using resonance frequency analysis. Clin. Oral Implant. Res. 1996, 7, 261-267. [CrossRef]

20. Friberg, B.; Sennerby, L.; Linden, B.; Gröndahl, K.; Lekholm, U. Stability measurements of one-stage Brånemark implants during healing in mandibles. A clinical resonance frequency analysis study. Int. J. Oral Maxillofac. Surg. 1999, 28, 266-272. [CrossRef]

21. Huang, H.M.; Pan, L.C.; Lee, S.Y.; Chiu, C.L.; Fan, K.H.; Ho, K.N. Assessing the implant/bone interface by using natural frequency analysis. Oral Surg. Oral Med. Oral Pathol. Oral Radiol. Endodontology 2000, 90, 285-291. [CrossRef] [PubMed]

22. Blanco, J.; Alvarez, E.; Muñoz, F.; Liñares, A.; Cantalapiedra, A. Influence on early osseointegration of dental implants installed with two different drilling protocols: A histomorphometric study in rabbit. Clin. Oral Implant. Res. 2011, 21, 92-99. [CrossRef] [PubMed]

23. Carlsson, L.; Röstlund, T.; Albrektsson, B.; Albrektsson, T. Removal torques for polished and rough titanium implants. Int. J. Oral Maxillofac. Implant. 1988, 3, 21-24.

(C) 2017 by the authors. Licensee MDPI, Basel, Switzerland. This article is an open access article distributed under the terms and conditions of the Creative Commons Attribution (CC BY) license (http://creativecommons.org/licenses/by/4.0/). 